\title{
Portakal (citrus sinensis) budama atığı uygulamalarının toprak verimlilik parametrelerindeki değişim üzerine etkileri
}

\author{
The effects of pruning waste of citrus (Citrus sinensis) applications on the some \\ productivity parameter changes of the soil
}

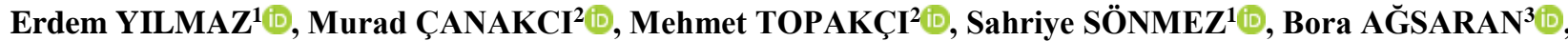 Zeki ALAGÖZ1 ${ }^{1}$, Sedat ÇITAK ${ }^{4}$, Dilek Saadet URAS $^{5}$ (D)}

${ }^{1}$ Akdeniz Üniversitesi, Ziraat Fakültesi, Toprak Bilimi ve Bitki Besleme Bölümü, Antalya

${ }^{2}$ Akdeniz Üniversitesi, Ziraat Fakültesi, Tarım Makinaları ve Teknolojileri Mühendisliği Bölümü, Antalya

${ }^{3}$ Batı Akdeniz Tarımsal Araștırma Enstitüsü, Antalya

${ }^{4}$ Dreamagri Tarım Danışmanlığı Ltd. Şti. Antalya

${ }^{5}$ Akdeniz Üniversitesi, Korkuteli Meslek Yüksekokulu, Antalya

Sorumlu yazar (Corresponding author): E. Y1lmaz, e-posta (e-mail): erdemyilmaz@akdeniz.edu.tr

Yazar(lar) e-posta (Author e-mail): mcakanci@akdeniz.edu.tr, mtopakci@akdeniz.edu.tr, ssonmez@akdeniz.edu.tr, bora.agsaran@tarim.gov.tr, zalagoz@akdeniz.edu.tr, scitak@hotmail.com,dsuras@akdeniz.edu.tr

MAKALE BİLGISİ

Alınıș tarihi 12 Mart 2019

Düzeltilme tarihi 19 Nisan 2019

Kabul tarihi 26 Nisan 2019

\section{Anahtar Kelimeler:}

Portakal budama atığ 1

Toprak işleme

Toprak verimliliği

\section{ÖZ}

Bu çalıșmanın amacı, portakal (Citrus cinensis var. "Washington Navel") budama atığının (PBA) iki farklı toprak işleme aletiyle (freze ve diskaro) toprağa uygulanmasının bazı toprak verimlilik parametrelerindeki değişim üzerine etkilerini belirlemektir. Her yıl yapılan budamalar sonras budama atıkları kuyruk milinden hareketli parçalama makinesi ile parçalama ișleminden sonra toprağa uygulanmıştır. Yapılan uygulamalar sonunda budama atıklarının belirlenen toprak verimlilik parametreleri üzerine olan etkileri $0-10 \mathrm{~cm}$ ve $10-20 \mathrm{~cm}$ derinliklerinden alınan toprak örneklerinde tespit edilmiştir. Çalışmada, budama atıkları kuru madde temel alınarak $306.0 \mathrm{~kg} \mathrm{da}^{-1}$ olacak şekilde toprağa uygulanmıslardır. Calıșmada, özellikle denemenin ikinci yılında toprağın organik madde $(\mathrm{OM})$, katyon değişim kapasitesi (KDK), toplam azot $(\mathrm{N})$, yarayışlı fosfor $(\mathrm{P})$, kalsiyum $\left(\mathrm{Ca}^{+2}\right)$, potasyum $\left(\mathrm{K}^{+}\right)$, bakır $\left(\mathrm{Cu}^{+2}\right)$ ve çinko $\left(\mathrm{Zn}^{+2}\right)$ miktarları ile elektriksel iletkenlik $(\mathrm{EC})$ değerlerinde önemli artışlar elde edilmiștir. Diğer taraftan, hacim ağırlığı, toprak reaksiyonu $(\mathrm{pH})$ değerleri ile değişebilir sodyum $\left(\mathrm{Na}^{+}\right)$, demir $\left(\mathrm{Fe}^{+3}\right)$ ve mangan $\left(\mathrm{Mn}^{+2}\right)$ miktarlarında azalma meydana geldiğ belirlenmiştir. Araştırmanın ikinci yılında, diskaro ile yapılan PBA uygulamaları toprağın yarayışı su (YS) miktarında önemli düzeyde artıs sağlarken dönemler arasında önemli bir farklılık meydana gelmemiştir. Elde edilen sonuçlar dikkate alındığında; PBA'nın bu yolla değerlendirilmesinin toprak verimliliği ve çevre açısından önemli faydalar sağlayabileceği öngörülmektedir.

\section{ARTICLE INFO}

Received 12 March 2019

Received in revised form 19 April 2019

Accepted 26 April 2019

\section{Keywords:}

Orange Pruning Waste

Soil Tillage

Soil Fertility

\begin{abstract}
The purpose of this experiment was to determine the effect of orange (Citrus cinensis var "Washington Navel") pruning waste (OPW) applications with two soil tillage equipment (disk harrow and freeze) on changes in some productivity parameters of soil. OPW applied for two years after the power take off (PTO) driven pruning residue chopper. At the end of the application, effects of OPW on soil properties were determined in soil samples obtained from $0-10$ and $10-20 \mathrm{~cm}$ soil depth. In the experiment, OPW applications to soil based on dry matter as $306.0 \mathrm{~kg} \mathrm{da}^{-1}$ every two years after the pruning is done. In the study, especially in the second year of the experiment, organic matter $(\mathrm{OM})$, cation exchange capacity $(\mathrm{KDK})$, total nitrogen $(\mathrm{N})$, phosphorus $(\mathrm{P})$, calcium $\left(\mathrm{Ca}^{+2}\right)$, potassium $\left(\mathrm{K}^{+}\right)$, copper $\left(\mathrm{Cu}^{+2}\right)$ and electrical conductivity $(\mathrm{EC})$ values have increased significantly in both depths of the soil. On the other hand, it was determined that the value of bulk density (HA), soil reaction $(\mathrm{pH})$, amount of changeable sodium $\left(\mathrm{Na}^{+}\right)$, iron $\left(\mathrm{Fe}^{+3}\right)$ and manganese $\left(\mathrm{Mn}^{+2}\right)$ decreased with the applications. OPW applications showed a significant increase in the amount of available water (AW) in the second year of the experiment, but did not make a significant difference between the periods. Considering the results obtained in this project; the use of OPW on a regular basis will benefit in terms of soil productivity and environment.
\end{abstract}

\section{Giriş}

Toprak organik maddesi toprakların fiziksel, kimyasal ve biyolojik özelliklerinin geliştirilmesi bakımından oldukça önemlidir. Özellikle de düzensiz yağıș rejimine sahip Akdeniz iklim koşulları altında bulunan birçok özelliği bozulmuş 
toprakların iyileştirilmesi açısından organik kökenli kaynakların kullanımı önem arz etmektedir. Ülkemiz genelindeki topraklarda olduğu gibi Antalya ve çevresinde yer alan birçok tarım toprağının organik madde kapsamı oldukça düşüktür.

Akdeniz bölgesinde oldukça farklı alanlarda tarımsal üretim gerçekleştirilmekte, bu faaliyetler sonucu oluşan birçok tarımsal atık ise gelişi güzel çevreye terk edilmekte veya yakılarak berteraf edilmeye çalışılmaktadır. Tarımsal atıkların çevreye terk edilmesi çevre açısından önemli riskleri barındırmakla birlikte tarımsal atıkların yakılması hem çevresel hem de topraklar için önemli olan karbon kaynakları heba edilmektedir. Türkiye'deki bahçe tarımından (kayısı, vişne, zeytin, antepfistığı, ceviz, badem, findık, limon, portakal, mandarin, greyfurt) meydana gelen atık miktarı toplam 5.166.413 ton'dur. $\mathrm{Bu}$ toplam miktar içerisinde Akdeniz bölgesinden elde edilen atık miktarı ise; yıllık 288.567 ton'dur (Başçetinçelik ve ark. 2005).

Günümüzde birçok ülkenin ilgili birimleri, atıkların yakılmasının çevreye verdiği olumsuz etkinin engellenmesi ve toprakların korunumu açısından söz konusu atıkların toprakla karıştırılarak değerlendirilmesini teşvik etmektedir. Degrede olmuş toprakların ıslahında tarımsal atıkların kullanımı Avrupa Birliği yasalarında önemli bir konu olarak yer almaktadır. Avrupa Birliği ülkelerinde özellikle de Akdeniz İklim kuşağında yer alan güney ülkelerinde toprakların korunumu (EEA 2000) ve atık yönetimine dair (Directive 2008) yönetmelikler oldukça ilgi çekmektedir (César ve ark. 2009).

Aşırı toprak işleme, bitkisel üretimdeki süreklilik, bitkisel kalıntıların toprak ortamından uzaklaştırılması, pestisit ve gübre kullanımındaki aşırılıklar gibi toprakların bozulmasını ilerleten tarımsal uygulamalar tarımsal sürdürülebilirliği azaltmaktadır (Dalal ve ark. 1995, Lee ve Pankhurst 1992). Toprak organik maddesi; toprağın verimlilik parametrelerinde ve bitkisel üretimin ekonomik düzeydeki devamlılı̆̆ gibi birçok alanda oldukça önemli bir faktördür (Juo ve Lal 1997). Yarı kurak bölge topraklarında görülen en ciddi ve yaygın problem bu bölgelerdeki vejetasyonun seyrek olması nedeniyle organik madde kapsamlarındaki düşüklüktür. Akdeniz iklim kuşağındaki bazı alanlarda bu durum daha da kötüleşmektedir (Lopez-Bermudez 1990). Akdeniz iklim koşulları altındaki topraklarda bu iklime özgü bitkilerin gelişiminin teşvik edilmesi ve organik kökenli materyallerin toprağa uygulanması bozulan toprak özelliklerin 1slahında oldukça önemlidir (Chaudhuri ve ark. 2013; Shazana ve ark. 2013). Budama atıklarının veya diğer tarımsal atıkların toprak verimlilik parametreleri üzerine etkileri üzerine yapılan çalışmalarda organik kökenli atık uygulamalarının toprağın $\mathrm{pH}, \mathrm{EC}$, organik karbon, makro ve mikro bitki besin maddeleri, katyon değişim kapasitesi ile birçok fiziksel ve biyolojik toprak parametresinde önemli değişimler meydana getirdiği ifade edilmiştir (Novara ve ark. 2011; Jiménez ve ark. 2013; Chaudhuri ve ark. 2013; HuesoGonzález ve ark. 2014).

$\mathrm{Bu}$ araştırmada, toprak verimliliğinin geliştirilmesinde kilit rol oynayan toprak organik maddesinin arttırılması ve atık uygulamalarının bazı toprak verimlilik parametrelerindeki değişim üzerine etkilerinin izlenmesi amaçlanmıştır. Bu amaçla portakal budama atıkları kuyruk milinden hareketli budama atığı parçalama makinasıyla parçalanmış, parçalanan budama atıklariiki farklı toprak işleme makinası ile (diskaro ve freze) toprağa uygulanmıştır.

\section{Materyal ve Metot}

Kuyruk milinden hareketli budama atığı parçalama makinesi tarafından parçalanan portakal budama atıkları (PBA) herhangi bir işleme tabi tutulmadan diskaro ve freze olmak üzere iki farklı toprak işleme makinesi ile 0-20 cm toprak derinliğine karıştırılmıştır (Şekil 1).

Denemelerde tandem tip, 28 diske sahip bir diskli tırmık ve L tipi bıçaklara sahip toprak frezesi kullanılmıştır. Budama atıklarının parçalanmasında kullanılan kuyruk milinden hareketli budama atığı parçalama makinesinde materyal besleme yoğunluğu yaklaşık $0.75 \mathrm{~kg} \mathrm{~s}^{-1}$ olarak dikkate alınmıştır. Budama artıklarının ortalama geometrik çapları, aynı makineyi kullanarak yapılan bir çalışmada güç tüketimi, uygun besleme yoğunlukları ve uygun ürünlerdeki çalışma koşulları göz önünde bulundurularak $13.03 \mathrm{~mm}$ olarak belirlenmiştir (Çanakçı ve ark. 2010). PBA'nın parçalanması sırasında makine ilerleme hızı $1.3 \mathrm{~km} \mathrm{~h}^{-1}$ iş genişliği $1.65 \mathrm{~m}$ olan parçalama makinası ile birim üretim alanı başına uygulanan materyal miktarı kuru bazda $306 \mathrm{~kg} \mathrm{da}^{-1}$ olarak belirlenmiştir. PBA'nın toprağa uygulanması anındaki nem düzeyi \%32 olarak tespit edilmiştir. Uygulanan atık miktarı ve uygulama yöntemleri her iki deneme yılında aynı düzey ve şekillerde gerçekleştirilmiştir. Budama parçalama makinesine ait bazı teknik özellikler Çizelge 1'de verilmiştir.
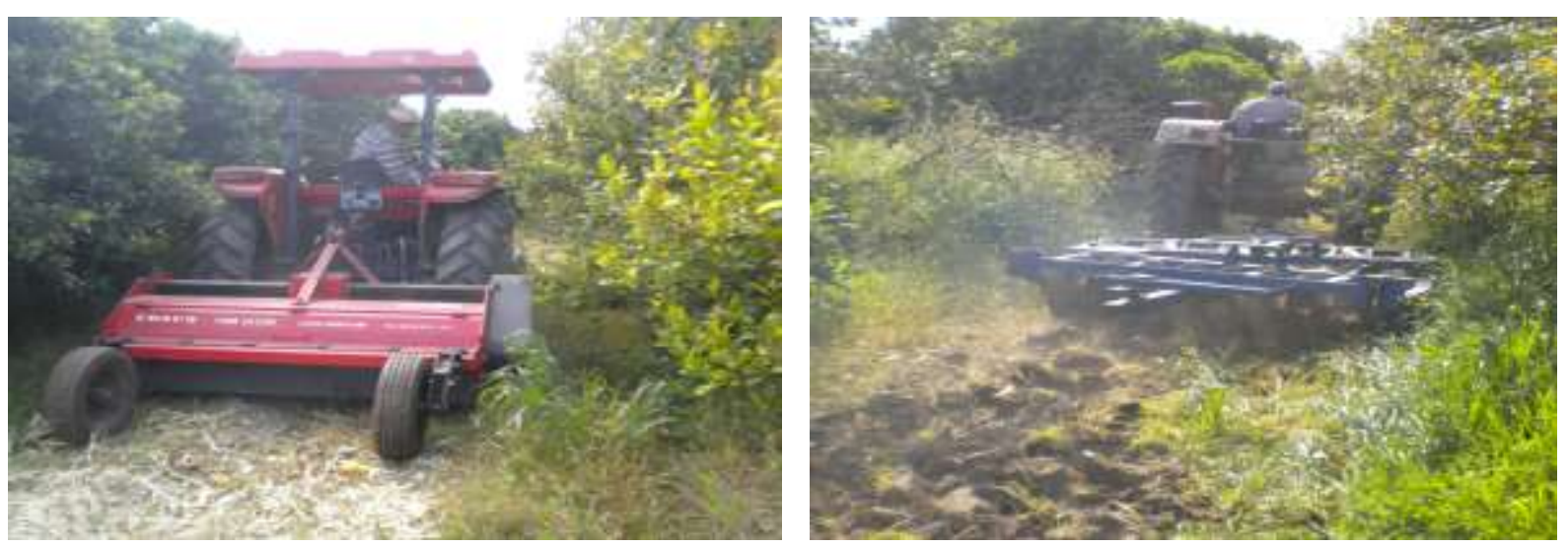

Şekil 1. Portakal budama artıklarının parçalanması ve uygulanması (A) Portakal budama atıklarının parçalanması (B) Portakal budama atıklarının toprağa uygulanması.

Figure 1. Chopping and application of orange pruning residues (A) Chopping of orange pruning residues (B) Application of orange pruning residues. 
Çizelge 1. Budama artığı parçalama makinesine ait bazı teknik özellikler.

Table 1. Some technical specifications of pruning shredder (PTO).

\begin{tabular}{|c|c|c|c|}
\hline Özellik & Değer & Özellik & Değer \\
\hline $\begin{array}{l}\text { Toplam uzunluk } \\
(\mathrm{mm})\end{array}$ & 1400 & $\begin{array}{l}\text { Toplam bıçak sayısı } \\
\text { (adet) }\end{array}$ & 54 \\
\hline $\begin{array}{l}\text { Toplam genişlik } \\
(\mathrm{mm})\end{array}$ & 2040 & $\begin{array}{l}\text { Parçalama ünitesi } \\
\text { devri }\left(\min ^{-1}\right)\end{array}$ & 1827 \\
\hline $\begin{array}{l}\text { Toplam yükseklik } \\
\text { (mm) }\end{array}$ & 1200 & $\begin{array}{l}\text { Bıçakların çevre hızı } \\
\left(\mathrm{m} \mathrm{s}^{-1}\right)\end{array}$ & 43.03 \\
\hline $\begin{array}{l}\text { Toplama genişliği } \\
(\mathrm{mm})\end{array}$ & 1700 & $\begin{array}{l}\text { Elek delik çap1 } \\
(\mathrm{mm})\end{array}$ & 36 \\
\hline Ağırlık (kg) & 800 & $\begin{array}{l}\text { Toplama ünitesi } \\
\text { devri }\left(\mathrm{min}^{-1}\right)\end{array}$ & 37 \\
\hline $\begin{array}{l}\text { Kuyruk mili devri } \\
\left(\min ^{-1}\right)\end{array}$ & 540 & Parmak sayısı (adet) & 19 \\
\hline $\begin{array}{l}\text { Biçak grubu sayısı } \\
\text { (adet) }\end{array}$ & 18 & $\begin{array}{l}\text { Parmakların çevre } \\
\text { hızı }\left(\mathrm{m} \mathrm{s}^{-1}\right)\end{array}$ & 0.91 \\
\hline
\end{tabular}

2011-2012 yılları budama dönemlerinde (Ocak-Mayıs) gerçekleştirilen denemeler Batı Akdeniz Tarımsal Araştırma Enstitüsü Müdürlüğü meyve bahçelerinde ( $36^{\circ} 55^{\prime} 51.65^{\prime \prime} \mathrm{K}$ ve $30^{\circ} 58^{\prime} 41.95^{\prime \prime}$ D) (Şekil 2) beş tekerrürlü olarak yürütülmüştür. Deneme alanı, Antalya ili merkezine $30 \mathrm{~km}$ mesafede Antalya'nın doğusunda bulunan Kayaburnu beldesinde yer almaktadır (Şekil 2). Deneme alanında yer alan portakal bahçesi 1991 yılında kurulmuş olup sıra aras1 ve sıra üzeri mesafe 6x6 $\mathrm{m}$ dir. Uygulamalar her bir siras1 $50 \mathrm{~m}$ olan ve her bir sira üzerinde $10 \mathrm{~m}$ lik parseller olarak belirlenen sira üzerinde gerçekleştirilmiştir. Denemenin yürütüldüğü 2011 ve 2012 yıllarında Antalya ili yıllık yağış miktarı ortalama $800 \mathrm{~mm}$ ve $1100 \mathrm{~mm}$ olarak gerçekleşmiştir (Meteoroloji Genel Müdürlüğü 2015).

Toplamada iki y1l olan deneme süresinin her bir yıllık uygulama süresi sonunda PBA'nın toprak verimlilik parametreleri üzerine olan etkileri $0-10 \mathrm{~cm}$ ve $10-20 \mathrm{~cm}$ toprak derinliğinden alınan toplam 30 örnekte belirlenen analizlerle tespit edilmiştir. Araştırma alanı topraklarına ait bazı fiziksel ve kimyasal özellikler Çizelge 2, PBA'nın yapısal özelliklerine ait bazı analiz sonuçları ise Çizelge 3 de verilmiştir.

\section{1. Toprak analiz yöntemleri}

Portakal budama atığı (PBA) uygulamalarının iki yıllık bir uygulama süresi sonunda toprağın fiziksel ve kimyasal özelliklerine etkilerini belirlemek için bazı analizler yapılmıştır. Yapılan analizlerden toprak tekstürü (Bouyoucos 1953), hacim ağırlığı (Black 1965), tarla kapasitesi, solma noktası ve toprağın yarayışlı su kapasitesi (Demiralay 1993) yöntemleri kullanılarak belirlenmiştir. Toprak reaksiyonu (pH) (Jackson 1967), elektriksel iletkenlik (EC) (Rhoades 1982), kireç $\left(\mathrm{CaCO}_{3}\right)$ (Çağlar, 1949) ve organik madde (Black 1965) yöntemlerine göre belirlenmiştir. Toprağın makro bitki besin elementlerinden toplam azot (N) (Kacar 1995), alınabilir fosfor (P) (Olsen ve Sommers 1982), değişebilir potasyum $\left(\mathrm{K}^{+}\right)$, kalsiyum $\left(\mathrm{Ca}^{+2}\right)$, magnezyum $\left(\mathrm{Mg}^{+2}\right)$ ve sodyum $\left(\mathrm{Na}^{+}\right)$(Kacar 1995) yöntemleri kullanılarak belirlenmiştir. Toprağın mikro besin elementlerinden alınabilir demir $\left(\mathrm{Fe}^{+3}\right)$, çinko $\left(\mathrm{Zn}^{+2}\right)$, mangan $\left(\mathrm{Mn}^{+2}\right)$ ve bakır $\left(\mathrm{Cu}^{+2}\right)$ (Lindsay ve Norwell 1978) yöntemleri kullanılarak belirlenmiştir. Toprağın katyon değişim kapasitesi (KDK) (Chapman ve Pratt 1961) yöntemi kullanılarak belirlenmiştir.

\section{2. Organik materyal analiz yöntemleri}

Parçacıkların Geometrik Çapı: Parçalama işlemi sonunda örneklere ait parçalanmış materyal boyutları (uzunluk, genişlik, kalınlık) kumpas ile ölçülerek, ağırlıkları ise hassas terazi ile tartılmıştır. Parçalanan materyalin geometrik ortalama çapının sınıflandırılmasında; beş adet frekans aralığı $x_{i}<4,4 \leq x_{i}<7$, $7 \leq x_{i}<10,10 \leq x_{i}<13$ ve $x_{i} \geq 13$ kullanılmıştır. Parçacıkların ortalama geometrik çaplarının belirlenmesinde aşağıdaki eşitlikler kullanılmıştır (Şeflek ve ark. 2006).

$$
D_{\text {geo }}=\sqrt[3]{U \cdot G \cdot K}
$$

Burada;

$D_{\text {geo }}=$ Geometrik ortalama çap $(\mathrm{mm})$,

$U=$ Parça uzunluğu (mm),

$G=$ Parça genişliği $(\mathrm{mm})$,

$K=$ Parçacık kalınlığ $1(\mathrm{~mm})$ 'dır.

$$
\delta_{\text {ort }}=\sum_{i=1}^{n} x_{i} \cdot f_{i}
$$

Burada;

$\delta_{\text {ort }}=$ Örneğin geometrik ortalama çap1 (mm),

$x_{i}=\mathrm{i}$. sınıftaki belirlenen geometrik ortalama çap $(\mathrm{mm})$,

$f_{i}=\mathrm{i}$. sınıftaki materyal miktarının tüm örnek kütlesine göre $\%$ değeri,

$\mathrm{n}=$ Sinıf sayısıdır.

Portakal budama atıklarının organik madde (OM) kapsamı (DIN 1978) \% nem (Kacar 1995) toplam azot (N), fosfor (P), potasyum $\left(\mathrm{K}^{+}\right)$, kalsiyum $\left(\mathrm{Ca}^{+2}\right)$, magnezyum $\left(\mathrm{Mg}^{+2}\right)$, sodyum $\left(\mathrm{Na}^{+}\right)$, demir $\left(\mathrm{Fe}^{+3}\right)$, çinko $\left(\mathrm{Zn}^{+2}\right)$, mangan $\left(\mathrm{Mn}^{+2}\right)$ ve bakır $\left(\mathrm{Cu}^{+2}\right)$ (Kacar ve İnal 2008) yöntemlerine göre belirlenmiştir.

\section{3. Istatistiksel analiz yöntemleri}

Tüm veriler DUNCAN çoklu karşılaştırma testi ile analiz edilmiştir $(\mathrm{P} \leq 0.05)$. Çalışmada sunulan tüm sonuçlar ortalama değerler $(n=5)$ olarak ifade edilmiştir. İstatistiksel analizler MINITAP 16.1.1 paket programı kullanılarak yapılmıştır. 


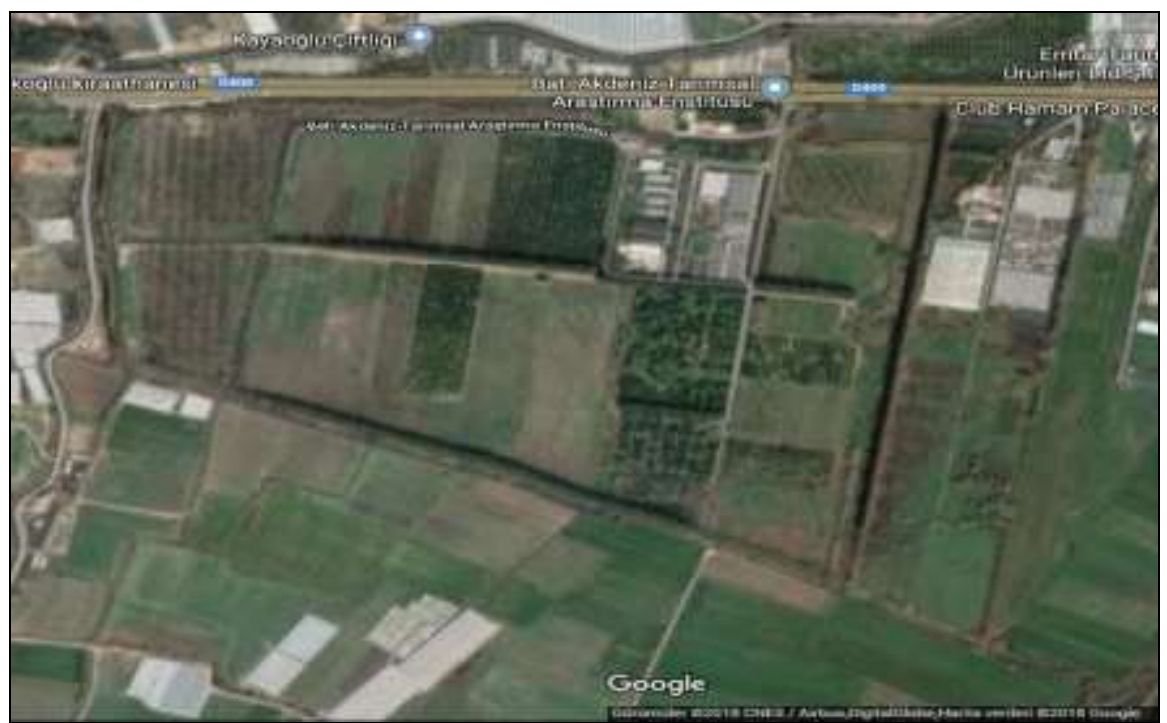

Şekil 2. Denemelerin gerçekleştirildiği alan.

Figure 2. Field of trials.

Çizelge 2. Deneme alanı topraklarına ait bazı analiz sonuçları.

Table 2. Some soil analysis results of the experimental area.

\begin{tabular}{|c|c|c|}
\hline \multirow{2}{*}{ Toprak Özellikleri } & \multicolumn{2}{|c|}{ Derinlik (cm) } \\
\hline & 0-10 & 10-20 \\
\hline Kum & 31.5 & 22.8 \\
\hline Silt & 41.5 & 45.7 \\
\hline Kil & 27.0 & 31.5 \\
\hline Tekstür & Killi Tin & Killi Tin \\
\hline $\mathrm{OM}(\%)$ & 1.36 & 1.35 \\
\hline $\mathrm{pH}(1 / 2)$ & 7.94 & 7.89 \\
\hline $\left.\mathrm{EC}(\mathrm{dS} \mathrm{m})^{-1}\right)$ & 0.182 & 0.182 \\
\hline $\mathrm{CaCO}_{3}(\%)$ & 27.16 & 24.33 \\
\hline Tarla Kapasitesi (\%) & 26.4 & 26.9 \\
\hline Solma Noktası (\%) & 15.3 & 14.6 \\
\hline Yarayışlı Su (\%) & 11.1 & 12.2 \\
\hline Hacim Ağırlığ $1\left(\mathrm{~g} \mathrm{~cm}^{-3}\right)$ & 1.37 & 1.38 \\
\hline $\operatorname{KDK}\left(\mathrm{cmol}_{\mathrm{c}} \mathrm{kg}^{-1}\right)$ & 16.40 & 15.25 \\
\hline $\operatorname{Azot}(\mathrm{N})(\%)$ & 0.099 & 0.095 \\
\hline Fosfor (P) $\mathrm{mg} \mathrm{kg}^{-1}$ & 65.0 & 58.8 \\
\hline Potasyum (K) mg kg-1 & 24.88 & 18.98 \\
\hline $\operatorname{Kalsiyum}(\mathrm{Ca}) \mathrm{mg} \mathrm{kg}^{-1}$ & 642.32 & 638.44 \\
\hline Magnezyum $(\mathrm{Mg}) \mathrm{mg} \mathrm{kg}^{-1}$ & 39.6 & 41.6 \\
\hline Sodyum (Na) mg kg-1 & 11.24 & 11.24 \\
\hline $\operatorname{Demir}(\mathrm{Fe}) \mathrm{mg} \mathrm{kg}^{-1}$ & 10.1 & 10.3 \\
\hline Mangan (Mn) $\mathrm{mg} \mathrm{kg}^{-1}$ & 7.4 & 7.7 \\
\hline Bakır $(\mathrm{Cu}) \mathrm{mg} \mathrm{kg}^{-1}$ & 3.3 & 3.0 \\
\hline Çinko (Zn) mg kg-1 & 0.20 & 0.19 \\
\hline
\end{tabular}

Çizelge 3. Portakal budama atıklarına (PBA) ait bazı analiz sonuçları.

Table 3. Some analysis results of the orange pruning waste (OPW).

\begin{tabular}{lc}
\hline Parametre & Değer \\
\hline $\mathrm{pH}\left(1: 2.5 \mathrm{H}_{2} \mathrm{O}\right)$ & 5.78 \\
$\mathrm{EC}\left(\mathrm{dS} \mathrm{m}^{-1}\right)$ & 0.27 \\
Organik C $(\%)$ & 51.4 \\
$\mathrm{C} / \mathrm{N}$ & 257 \\
$\mathrm{~N}(\%)$ & 0.20 \\
$\mathrm{P}\left(\mathrm{mg} \mathrm{kg}^{-1}\right)$ & 784.2 \\
$\mathrm{~K}\left(\mathrm{mg} \mathrm{kg}^{-1}\right)$ & 3649 \\
$\mathrm{Ca}\left(\mathrm{mg} \mathrm{kg}^{-1}\right)$ & 3154 \\
$\mathrm{Mg}\left(\mathrm{mg} \mathrm{kg}^{-1}\right)$ & 2431 \\
$\mathrm{Fe}\left(\mathrm{mg} \mathrm{kg}^{-1}\right)$ & 1858 \\
$\mathrm{Zn}\left(\mathrm{mg} \mathrm{kg}^{-1}\right)$ & 8.2 \\
$\mathrm{Mn}\left(\mathrm{mg} \mathrm{kg}^{-1}\right)$ & 34.1 \\
$\mathrm{Cu}\left(\mathrm{mg} \mathrm{kg}^{-1}\right)$ & 107.8 \\
\hline
\end{tabular}

\section{Bulgular ve Tartışma}

Portakal budama atığı (PBA) uygulamalarının iki farklı derinlikteki (0-10 ve 10-20 cm) toprak reaksiyonu $(\mathrm{pH})$ üzerine etkisi denemenin birinci y1lında $0-10 \mathrm{~cm}$ derinliği dişında $(P<0.05)$ önemli bulunmamıştır. Yapılan uygulamalar ile dönemler arasında önemli farklılıklar elde edilmiş olup tüm uygulama konularında toprağın $\mathrm{pH}$ değerlerinin ikinci yılda azalma gösterdiği belirlenmiştir (Çizelge 4).

Portakal budama atığı (PBA) uygulamalarının iki farklı derinliğe sahip toprağın elektriksel iletkenlik (EC) değeri üzerine etkisi denemenin her iki yılında önemli bulunmuştur. Denemenin birinci yllında PBA uygulamalarıyla her iki derinlikteki toprağın EC değerlerinde düşüş gerçekleşmiştir. Hem diskaro hem de freze ile yapılan PBA uygulamasının EC üzerine etkisi istatistiksel anlamda benzer bulunmuştur. Denemenin ikinci yılında, PBA uygulamaları toprağın EC değerinde artış meydana getirmiştir. Her iki toprak işleme aletiyle yapılan PBA uygulaması etki bakımından aynı grupta yer almıştır. Bununla birlikte tüm uygulama konularında toprakların EC değerlerinde dönemler arasında istatistiksel anlamda önemli farklılıkların bulunduğu, toprakların EC değerlerinin PBA uygulamaları ile denemenin birinci yılına göre ikinci yılında artış gösterdiği belirlenmiştir (Çizelge 4).

Portakal budama atığı (PBA) uygulamaları toprağın organik madde (OM) kapsamında denemenin her iki yılında da istatistiksel anlamda önemli farklılıklar meydana getirmiştir. İki farklı toprak işleme aletiyle yapılan PBA uygulamaları her iki derinlikteki toprağın OM kapsamında artışa neden olmuştur. PBA uygulamalarının dönemsel etkileri incelendiğinde freze ile yapılan PBA uygulaması ile her iki derinlikteki toprağın OM kapsamının önemli artış gösterdiği belirlenmiştir (Çizelge 4).

Portakal budama atığı (PBA) uygulamalarının toprağın yarayışlı su kapasitesi (YSK) üzerine etkisi denemenin birinci y1lında ve her iki toprak derinliğinde önemli bulunmamıştır. Denemenin ikinci yllında ise diskaro ile gerçekleştirilen PBA uygulaması her iki derinlikteki toprağın YSK değerinde artış sağlayan uygulama olmuştur. Dönemsel farklılıklara bakıldığında kontrol grubunda yer alan toprakların YSK değerlerinde önemli düşüşler meydana gelirken PBA 
uygulamalarının yapıldığı konularda önemli düzeyde bir farklılık oluşmamıştır (Çizelge 4).

Portakal budama atığı (PBA) uygulamalarının toprağın hacim ağırlığ 0-10 cm toprak derinliği hariç önemli bulunmuştur. Özellikle diskaro ile gerçekleştirilen PBA uygulamaları toprağın HA değerlerinde önemli düşüşler sağlamıştır. Uygulamalar arasındaki dönemsel farklılıklara bakıldığında ise kontrol grubu olan toprakların HA değerlerinde önemli artış meydana gelirken PBA uygulamalarının yapıldığ 1 konularda önemli bir farklılık meydana gelmemiştir (Çizelge 4).

Portakal budama atığı (PBA) uygulamalarının toprağın katyon değişim kapasitesi (KDK) üzerine etkisi denemenin birinci yılının 0-10 $\mathrm{cm}$ toprak derinliği dışında her iki yıl ve toprak derinliğinde istatistiksel anlamda önemli olmuştur. Her iki yıl ve toprak derinliğinde toprağın KDK değerlerinde en önemli artış sağlayan uygulama diskaro ile gerçekleştirilen PBA uygulamaları olmuştur. Bununla birlikte diskaro ve freze ile yapılan PBA uygulamaları ile özellikle $0-10 \mathrm{~cm}$ toprak derinliğinde toprağın $\mathrm{KDK}$ değerlerinde ikinci yılda daha yüksek değerler elde edilmiştir (Çizelge 4)

Diskaro ve freze olmak üzere iki farklı toprak işleme yöntemiyle gerçekleştirilen PBA uygulamalarının toprağın azot (N) kapsamı üzerine etkisi denemenin birinci yılında ve 0-10 $\mathrm{cm}$ toprak derinliğinde istatistiksel anlamda $(P<0.01)$ önemli olmuştur. Denemenin ilk yılında PBA uygulamaları ile toprağın $\mathrm{N}$ kapsamında azalma meydana gelmiștir. Uygulamaların 10-20 $\mathrm{cm}$ toprak derinliğindeki etkisi ise önemli bulunmamıştır. Denemenin ikinci yılında, PBA uygulamalarının her iki toprak derinliğindeki $\mathrm{N}$ kapsamı üzerine etkisi istatistiksel anlamda önemli bulunmuş, uygulamalar ile toprağın $\mathrm{N}$ kapsamında artış elde edilmiştir. Uygulamaların dönemsel etkileri karşılaştırıldığında ise PBA uygulamaları ile toprakların N kapsamında denemenin ikinci yılında daha fazla artış elde edilmiştir (Çizelge 5).

Portakal budama atığı (PBA) uygulamalarının toprağın fosfor $(\mathrm{P})$ kapsamı üzerine etkisi denemenin birinci yılında ve her iki toprak derinliğinde önemli bulunmazken denemenin ikinci yılında PBA uygulamaları ile her iki derinliğe sahip toprağın $\mathrm{P}$ kapsamında istatistiksel anlamda önemli $(P<0.001)$ artışlar elde edilmiştir (Çizelge 5).

Portakal budama atığı (PBA) uygulamalarının toprağın potasyum $\left(\mathrm{K}^{+}\right)$kapsamı üzerine etkisi denemenin her iki yılı ve toprak derinliğinde istatistiksel anlamda önemli bulunmamıştır. Uygulamaların dönemsel etkileri incelendiğinde ise üst toprak katmanındaki $(0-10 \mathrm{~cm}) \mathrm{K}$ kapsamının denemenin birinci yılına göre ikinci yılında artış gösterdiği belirlenmiştir (Çizelge 5).

Portakal budama atığı (PBA) uygulamalarının toprağın kalsiyum $\left(\mathrm{Ca}^{+2}\right)$ kapsamı üzerine etkisi denemenin birinci y1lında ve $0-10 \mathrm{~cm}$ toprak derinliğinde, ikinci y1lında ise $10-20$ $\mathrm{cm}$ toprak derinliğinde önemli bulunmuştur. Denemenin birinci yılında her iki toprak işleme aletiyle yapılan PBA uygulamalarının toprağın $\mathrm{Ca}^{+2}$ kapsamında artış sağlarken ikinci yılda diskaro ile yapılan PBA uygulamalarıyla toprağın $\mathrm{Ca}^{+2}$ içeriğinde azalma meydana gelmiştir. Bununla birlikte, $0-10 \mathrm{~cm}$ toprak derinliğinde tüm deneme konularında, 10-20 cm toprak derinliğinde ise freze ile yapılan PBA uygulamasıyla dönemler arasında istatistiksel anlamda önemli farklılıklar meydana gelmiştir (Çizelge 5).

Çizelge 4. Portakal budama atığı (PBA) uygulamalarının toprak reaksiyonu (pH), elektriksel iletkenlik (EC), organik madde (OM), yarayışlı su kapasitesi (YS), hacim ağırlığı (HA) ve katyon değişim kapasitesi (KDK) üzerine etkisi ${ }^{1}$.

Table 4. Effects of orange pruning waste (OPW) applications on soil reaction $(\mathrm{pH})$, electrical conductivity $(\mathrm{EC})$, organic matter (OM), available water capacity (AWC), bulk density (BD) and cation exchange capacity (CEC)1.

\begin{tabular}{|c|c|c|c|c|c|c|c|c|c|c|}
\hline \multirow{3}{*}{$\begin{array}{c}\text { Derinlik } \\
(\mathrm{cm})\end{array}$} & \multirow{3}{*}{$\begin{array}{l}\text { Toprak } \\
\text { İşleme } \\
\text { Metodu }\end{array}$} & \multicolumn{3}{|c|}{$\mathrm{pH}(1: 2.5)$} & \multicolumn{3}{|c|}{$\mathrm{EC}\left(\mathrm{dS} \mathrm{m} \mathrm{m}^{-1}\right)$} & \multicolumn{3}{|c|}{$\mathrm{OM}(\%)$} \\
\hline & & \multicolumn{2}{|c|}{ Dönem } & \multirow{2}{*}{$\begin{array}{l}\text { ANOVA } \\
\text { (Dönem) }\end{array}$} & \multicolumn{2}{|c|}{ Dönem } & \multirow{2}{*}{$\begin{array}{l}\text { ANOVA } \\
\text { (Dönem) }\end{array}$} & \multicolumn{2}{|c|}{ Dönem } & \multirow{2}{*}{$\begin{array}{l}\text { ANOVA } \\
\text { (Dönem) }\end{array}$} \\
\hline & & 1. Y11 & 2. Yil & & 1. Y11 & 2. Yil & & 1. Yil & 2. Y11 & \\
\hline \multirow{4}{*}{$0-10$} & Kontrol & $8.04 \mathrm{bA}^{2}$ & $7.32 \mathrm{~B}$ & $* * *$ & $0.350 \mathrm{aB}$ & $0.778 \mathrm{bA}$ & $* *$ & $1.08 \mathrm{bB}$ & $1.36 \mathrm{bA}$ & $*$ \\
\hline & Diskaro & $8.36 \mathrm{aA}$ & 7.37B & $* * *$ & $0.198 \mathrm{bB}$ & $1.564 \mathrm{aA}$ & $* * *$ & $1.45 \mathrm{a}$ & $1.59 \mathrm{~b}$ & öd \\
\hline & Freze & $8.15 \mathrm{bA}$ & $7.44 \mathrm{~B}$ & $* * *$ & $0.175 \mathrm{bB}$ & $1.838 \mathrm{aA}$ & $* * *$ & $1.36 \mathrm{aB}$ & $2.16 \mathrm{aA}$ & $* *$ \\
\hline & ANOVA $^{3}$ & $*$ & öd & & $* *$ & $* * *$ & & $* *$ & $* *$ & \\
\hline \multirow{4}{*}{$10-20$} & Kontrol & $8.04 \mathrm{~A}$ & $7.36 \mathrm{~B}$ & $* * *$ & $0.242 \mathrm{aB}$ & $0.628 \mathrm{bA}$ & $* *$ & $1.00 \mathrm{c}$ & $1.14 \mathrm{c}$ & öd \\
\hline & Diskaro & $8.29 \mathrm{~A}$ & $7.42 \mathrm{~B}$ & $* * *$ & $0.186 \mathrm{bB}$ & $1.717 \mathrm{aA}$ & $* * *$ & $1.72 \mathrm{a}$ & $1.90 \mathrm{~b}$ & öd \\
\hline & Freze & $8.27 \mathrm{~A}$ & $7.68 \mathrm{~B}$ & $* *$ & $0.208 \mathrm{bB}$ & $1.737 \mathrm{aA}$ & $* * *$ & $1.43 \mathrm{bB}$ & $2.53 \mathrm{aA}$ & $* * *$ \\
\hline & ANOVA & öd & öd & & $* *$ & *** & & $* * *$ & $* * *$ & \\
\hline \multirow{3}{*}{$\begin{array}{l}\text { Derinlik } \\
(\mathrm{cm})\end{array}$} & \multirow{3}{*}{$\begin{array}{l}\text { Toprak } \\
\text { İşleme } \\
\text { Metodu }\end{array}$} & \multicolumn{3}{|c|}{ YS (\%) } & \multicolumn{3}{|c|}{$\mathrm{HA}\left(\mathrm{g} \mathrm{cm}^{-3}\right)$} & \multicolumn{3}{|c|}{$\mathrm{KDK}\left(\mathrm{cmol}_{\mathrm{c}} \mathrm{kg}^{-1}\right)$} \\
\hline & & \multicolumn{2}{|c|}{ Dönem } & ANOVA & \multicolumn{2}{|c|}{ Dönem } & ANOVA & \multicolumn{2}{|c|}{ Dönem } & ANOVA \\
\hline & & 1. Y11 & 2. Y11 & & 1. Y1l & 2. Y1l & & 1. Y1l & 2. Y1l & (Dönem) \\
\hline \multirow{4}{*}{$0-10$} & Kontrol & $12.90 \mathrm{~A}$ & $10.09 \mathrm{bB}$ & $*$ & $1.43 \mathrm{~B}$ & $1.45 \mathrm{aA}$ & $*$ & 20.49 & $21.16 \mathrm{c}$ & öd \\
\hline & Diskaro & 14.01 & $12.00 \mathrm{a}$ & öd & 1.41 & $1.38 \mathrm{~b}$ & öd & 20.60B & $23.69 \mathrm{aA}$ & $*$ \\
\hline & Freze & 14.16 & $10.37 \mathrm{~b}$ & öd & 1.42 & $1.39 \mathrm{~b}$ & öd & $18.85 \mathrm{~B}$ & $22.25 \mathrm{bA}$ & $*$ \\
\hline & ANOVA $^{3}$ & öd & $*$ & & öd & $* *$ & & öd & $* * *$ & \\
\hline \multirow{4}{*}{$10-20$} & Kontrol & $12.12 \mathrm{~A}$ & $9.06 \mathrm{cB}$ & $* *$ & $1.45 \mathrm{a}$ & $1.44 \mathrm{a}$ & öd & $19.82 b$ & $20.49 b$ & öd \\
\hline & Diskaro & 12.19 & $11.32 \mathrm{a}$ & öd & $1.42 \mathrm{~b}$ & $1.37 \mathrm{~b}$ & öd & $22.38 \mathrm{a}$ & $23.52 \mathrm{a}$ & öd \\
\hline & Freze & 12.41 & $10.44 \mathrm{~b}$ & öd & $1.46 \mathrm{a}$ & $1.41 \mathrm{a}$ & öd & $18.61 \mathrm{bB}$ & $21.01 \mathrm{bA}$ & $*$ \\
\hline & ANOVA & öd & $* *$ & & $*$ & $*$ & & $* *$ & $* *$ & \\
\hline
\end{tabular}

1. Değerler 5 tekerrür ortalamasıdır. 2. Aynı harfle gösterilmeyen değerler arasındaki farklar $\% 5$ düzeyinde önemlidir. 3. öd: Önemli değil, ${ }^{*} \% 5$ düzeyinde önemli, **: \% 1 düzeyinde önemli ***: $\% 0.1$ düzeyinde önemli. 
Çizelge 5. Portakal budama atığı uygulamalarının toprağın makro bitki besin elementi içeriği üzerine etkisi ${ }^{1}$. Table 5. The effect of orange pruning waste (OPW) applications on macro nutrient contents of soil ${ }^{1}$.

\begin{tabular}{|c|c|c|c|c|c|c|c|c|c|c|}
\hline \multirow{3}{*}{$\begin{array}{l}\text { Derinlik } \\
(\mathrm{cm})\end{array}$} & \multirow{3}{*}{$\begin{array}{l}\text { Toprak İşleme } \\
\text { Metodu }\end{array}$} & \multicolumn{3}{|c|}{$\mathrm{N}(\%)$} & \multicolumn{3}{|c|}{$\mathrm{P}\left(\mathrm{mg} \mathrm{kg}^{-1}\right)$} & \multicolumn{3}{|c|}{$\mathrm{K}\left(\mathrm{cmol} \mathrm{kg}{ }^{-1}\right)$} \\
\hline & & \multicolumn{2}{|c|}{ Dönem } & \multirow{2}{*}{$\begin{array}{l}\text { ANOVA } \\
\text { (Dönem) }\end{array}$} & \multicolumn{2}{|c|}{ Dönem } & \multirow{2}{*}{$\begin{array}{l}\text { ANOVA } \\
\text { (Dönem) }\end{array}$} & \multicolumn{2}{|c|}{ Dönem } & \multirow{2}{*}{$\begin{array}{l}\text { ANOVA } \\
\text { (Dönem) }\end{array}$} \\
\hline & & 1. Y11 & 2. $Y_{11}$ & & 1. Yil & 2. Y11 & & 1. Yil & 2. Y11 & \\
\hline \multirow{4}{*}{$0-10$} & Kontrol & $0.078 \mathrm{aB}^{2}$ & $0.147 \mathrm{bA}$ & $*$ & 59.77 & $75.47 b$ & öd & $0.415 \mathrm{~B}$ & $0.671 \mathrm{~A}$ & $*$ \\
\hline & Diskaro & $0.054 \mathrm{bB}$ & $0.167 \mathrm{bA}$ & $* * *$ & $61.72 \mathrm{~B}$ & $168.24 \mathrm{aA}$ & $* *$ & $0.386 \mathrm{~B}$ & $0.577 \mathrm{~A}$ & $*$ \\
\hline & Freze & $0.048 \mathrm{bB}$ & $0.214 \mathrm{aA}$ & $* * *$ & $62.09 \mathrm{~B}$ & $171.42 \mathrm{aA}$ & $* *$ & $0.451 \mathrm{~B}$ & $0.675 \mathrm{~A}$ & $* *$ \\
\hline & ANOVA $^{3}$ & $* *$ & $* *$ & & öd & $* * *$ & & öd & öd & \\
\hline \multirow{4}{*}{$10-20$} & Kontrol & $0.078 \mathrm{~B}$ & $0.114 \mathrm{cA}$ & $* *$ & 61.41 & $59.33 \mathrm{~b}$ & öd & 0.466 & 0.636 & öd \\
\hline & Diskaro & $0.072 \mathrm{~B}$ & $0.188 \mathrm{aA}$ & $* * *$ & $56.31 \mathrm{~B}$ & $133.18 \mathrm{aA}$ & $* *$ & 0.451 & 0.612 & öd \\
\hline & Freze & $0.042 \mathrm{~B}$ & $0.170 \mathrm{bA}$ & $* * *$ & $57.31 \mathrm{~B}$ & $148.49 \mathrm{aA}$ & $* *$ & 0.531 & 0.577 & öd \\
\hline & ANOVA & öd & $* * *$ & & öd & $* * *$ & & öd & öd & \\
\hline \multirow{3}{*}{$\begin{array}{l}\text { Derinlik } \\
(\mathrm{cm})\end{array}$} & \multirow{3}{*}{$\begin{array}{l}\text { Toprak İşleme } \\
\text { Metodu }\end{array}$} & \multicolumn{3}{|c|}{$\mathrm{Ca}\left(\mathrm{cmol} \mathrm{kg}^{-1}\right)$} & \multicolumn{3}{|c|}{$\mathrm{Mg}\left(\mathrm{cmol} \mathrm{kg}^{-1}\right)$} & \multicolumn{3}{|c|}{$\mathrm{Na}\left(\mathrm{cmol} \mathrm{kg}^{-1}\right)$} \\
\hline & & \multicolumn{2}{|c|}{ Dönem } & ANOVA & \multicolumn{2}{|c|}{ Dönem } & ANOVA & \multicolumn{2}{|c|}{ Dönem } & ANOVA \\
\hline & & 1. Y11 & 2. Y11 & (Dönem) & 1. Y1l & 2. Y1l & (Dönem) & 1. $Y_{11}$ & 2. Y11 & (Dönem) \\
\hline \multirow{4}{*}{$0-10$} & Kontrol & $17.34 \mathrm{bB}^{2}$ & $25.30 \mathrm{~A}$ & $* *$ & $2.07 \mathrm{~B}$ & $3.25 \mathrm{aA}$ & $* * *$ & 0.366 & $0.344 \mathrm{a}$ & öd \\
\hline & Diskaro & $23.19 \mathrm{aB}$ & $26.72 \mathrm{~A}$ & $* *$ & 2.47 & $2.34 \mathrm{~b}$ & öd & $0.306 \mathrm{~A}$ & $0.065 \mathrm{bB}$ & $* * *$ \\
\hline & Freze & $21.63 \mathrm{aB}$ & $27.44 \mathrm{~A}$ & $*$ & 2.49 & $2.43 b$ & öd & $0.300 \mathrm{~A}$ & $0.113 b B$ & $* * *$ \\
\hline & ANOVA $^{3}$ & $* *$ & öd & & öd & $* *$ & & öd & $* * *$ & \\
\hline \multirow{4}{*}{$10-20$} & Kontrol & 23.70 & $27.03 \mathrm{a}$ & öd & $2.13 \mathrm{~B}$ & $3.26 \mathrm{aA}$ & $*$ & 0.370 & $0.272 \mathrm{a}$ & öd \\
\hline & Diskaro & 22.30 & $23.97 b$ & öd & 2.57 & $2.07 \mathrm{~b}$ & öd & $0.322 \mathrm{~A}$ & $0.119 \mathrm{bB}$ & $* * *$ \\
\hline & Freze & $21.73 \mathrm{~B}$ & $26.37 \mathrm{aA}$ & $* * *$ & 2.59 & $2.99 \mathrm{a}$ & öd & $0.256 \mathrm{~A}$ & $0.101 \mathrm{bB}$ & $* *$ \\
\hline & ANOVA & öd & $*$ & & öd & $* *$ & & öd & $* *$ & \\
\hline
\end{tabular}

1. Değerler 5 tekerrür ortalamasıdır. 2. Aynı harfle gösterilmeyen değerler arasındaki farklar \%5 düzeyinde önemlidir. 3. öd: Önemli değil, *: \%5 düzeyinde önemli, **: \%1 düzeyinde önemli, ***: \%0.1 düzeyinde önemli

Portakal budama atı̆̆ı (PBA) uygulamalarının toprağın magnezyum $\left(\mathrm{Mg}^{+2}\right)$ kapsamı üzerine etkisi denemenin birinci y1lında ve her iki toprak derinliğinde istatistiksel anlamda önemli bulunmamıştır. Denemenin ikinci yılında, PBA uygulamalarının her iki toprak derinliğindeki $\mathrm{Mg}^{+2}$ kapsamı üzerine etkisi önemli $(P<0.01)$ bulunmuştur. $0-10 \mathrm{~cm}$ toprak derinliğinde her iki uygulama ile $10-20 \mathrm{~cm}$ toprak derinliğinde ise diskaro ile gerçekleştirilen PBA uygulamaları ile toprağın $\mathrm{Mg}^{+2}$ kapsamında azalma meydana gelmiştir. Ayrıca kontrol grupları dışında PBA uygulanan deneme konularında toprağın $\mathrm{Mg}^{+2}$ kapsamı bakımından dönemler arasında istatistiksel anlamda önemli bir farklılık meydana gelmemiştir (Çizelge 5).

Portakal budama atığı (PBA) uygulamalarının toprağın sodyum $\left(\mathrm{Na}^{+}\right)$kapsamı üzerine etkisi denemenin birinci yılında ve her iki toprak derinliğinde istatistiksel anlamda önemsiz bulunmuştur. Denemenin ikinci yılında, diskaro ve freze ile yapılan PBA uygulamaları her iki derinlikteki toprağın $\mathrm{Na}^{+}$ kapsamında önemli düzeyde azalma meydana getirmiştir. Benzer şekilde, PBA uygulamaları ile dönemler arasında da istatistiksel anlamda önemli farklılıklar meydana gelmiş, toprakların $\mathrm{Na}^{+}$kapsamları denemenin birinci yılına göre ikinci y1lında azalmıştır (Çizelge 5).

Portakal budama atığı (PBA) uygulamalarının toprağın demir $\left(\mathrm{Fe}^{+3}\right)$ kapsamı üzerine etkisi denemenin her iki yılında ve her iki toprak derinliğinde istatistiksel anlamda önemli bulunmamıştır. Ancak tüm uygulama konularında dönemler arasında toprağın $\mathrm{Fe}^{+3}$ kapsamı bakımından istatistiksel önemli farklılıklar meydana gelmiş ve toprağın $\mathrm{Fe}^{+3}$ kapsamı denemenin birinci yılına göre ikinci yılında azalmıştır (Çizelge $6)$.

Portakal budama atığı (PBA) uygulamalarının toprağın mangan $\left(\mathrm{Mn}^{+2}\right)$ kapsamı üzerine etkisi denemenin birinci yılındaki $0-10 \mathrm{~cm}$ toprak derinliği dışında istatistiksel anlamda önemli bulunmuştur. Denemenin birinci yılında 10-20 cm toprak derinliğinde freze ile gerçekleştirilen PBA uygulaması toprağın $\mathrm{Mn}^{+2}$ kapsamında artış meydana getirmiştir. Denemenin ikinci yılında, $0-15 \mathrm{~cm}$ toprak derinliğinde diskaro ile yapılan PBA uygulaması, 10-20 cm toprak derinliğinde ise her iki toprak işleme aletiyle yapılan PBA uygulamaları ile toprağın $\mathrm{Mn}^{+2}$ kapsamında azalma elde edilmiştir. Dönemsel etkiler incelendiğinde ise, $0-10 \mathrm{~cm}$ toprak derinliğinde diskaro ile $10-20 \mathrm{~cm}$ toprak derinliğinde ise freze ile yapılan PBA uygulamalarında dönemler arasında önemli farklılıklar bulunmuş ve toprakların $\mathrm{Mn}^{+2}$ kapsamlarında denemenin birinci yılına göre ikinci yılında azalma elde edilmiştir (Çizelge 6).

Portakal budama atığı (PBA) uygulamalarının toprağın çinko $\left(\mathrm{Zn}^{+2}\right)$ kapsamı üzerine etkisi denemenin birinci yılında 10-20 cm toprak derinliği dışında istatistiksel anlamda önemli bulunmuştur. Denemenin birinci yılında ve $0-10 \mathrm{~cm}$ toprak derinliğinde diskaro ile denemenin ikinci y1lında ise her iki toprak derinliğinde ve her iki toprak işleme aletiyle yapılan PBA uygulamalarıyla toprağın $\mathrm{Zn}^{+2}$ kapsamında azalma meydana gelmiştir. Dönemsel etki bağlamında ise, $0-10 \mathrm{~cm}$ toprak derinliğinde diskaro, $10-20 \mathrm{~cm}$ toprak derinliğinde ise freze ile yapılan PBA uygulamalarıyla dönemler arasında istatistiksel farkl1lıklar bulunmuştur. Diskaro ile yapılan PBA uygulamaları ile $0-10 \mathrm{~cm}$ toprak derinliğindeki $\mathrm{Zn}^{+2}$ içeriğinde artı̧s meydana gelirken, 10-20 cm toprak derinliğinde freze ile yapılan uygulama ile toprağın $\mathrm{Zn}^{+2}$ içeriğinde azalma meydana gelmiştir (Çizelge 6).

Portakal budama atığı (PBA) uygulamalarının toprağın bakır $\left(\mathrm{Cu}^{+2}\right)$ kapsamı üzerine etkisi denemenin birinci yılının $10-20 \mathrm{~cm}$ toprak derinliği dişında istatistiksel anlamda önemli bulunmuştur. Denemenin birinci yılında ve $0-10 \mathrm{~cm}$ toprak derinliğinde freze ile gerçekleştirilen PBA uygulamaları, denemenin ikinci yılında ise her iki toprak işleme aletiyle 
Çizelge 6 Portakal budama atığı uygulamalarının toprağın mikro bitki besin elementi içeriği üzerine etkisi ${ }^{1}$. Table 6. Effect of orange pruning waste (OPW) applications on micro nutrient contents of soil ${ }^{1}$.

\begin{tabular}{|c|c|c|c|c|c|c|c|}
\hline \multirow{3}{*}{$\begin{array}{l}\text { Derinlik } \\
(\mathrm{cm})\end{array}$} & \multirow{3}{*}{$\begin{array}{l}\text { Toprak İşleme } \\
\text { Metodu }\end{array}$} & \multicolumn{3}{|c|}{$\mathrm{Fe}\left(\mathrm{mg} \mathrm{kg}^{-1}\right)$} & \multicolumn{3}{|c|}{$\operatorname{Mn}\left(\mathrm{mg} \mathrm{kg}^{-1}\right)$} \\
\hline & & \multicolumn{2}{|c|}{ Dönem } & \multirow{2}{*}{$\begin{array}{l}\text { ANOVA } \\
\text { (Dönem) }\end{array}$} & \multicolumn{2}{|c|}{ Dönem } & \multirow{2}{*}{$\begin{array}{l}\text { ANOVA } \\
\text { (Dönem) }\end{array}$} \\
\hline & & 1. Y1l & 2. Yil & & 1. Y1l & 2. Y11 & \\
\hline \multirow{4}{*}{$0-10$} & Kontrol & $10.60 \mathrm{~A}^{2}$ & $5.75 \mathrm{~B}$ & $* * *$ & 7.55 & $7.25 \mathrm{a}$ & öd \\
\hline & Diskaro & $9.21 \mathrm{~A}$ & $5.76 \mathrm{~B}$ & $* *$ & $8.28 \mathrm{~A}$ & $4.25 \mathrm{bB}$ & $* * *$ \\
\hline & Freze & $8.82 \mathrm{~A}$ & $6.80 \mathrm{~B}$ & $*$ & 7.51 & $5.88 \mathrm{a}$ & öd \\
\hline & ANOVA $^{3}$ & öd & öd & & öd & $*$ & \\
\hline \multirow{4}{*}{$10-20$} & Kontrol & $9.59 \mathrm{~A}$ & $6.03 \mathrm{~B}$ & $* * *$ & $5.50 \mathrm{~b}$ & $6.95 a$ & öd \\
\hline & Diskaro & $8.93 \mathrm{~A}$ & $5.17 \mathrm{~B}$ & $* *$ & $4.73 b$ & $4.02 \mathrm{~b}$ & öd \\
\hline & Freze & $9.09 \mathrm{~A}$ & $6.08 \mathrm{~B}$ & $* *$ & $7.91 \mathrm{aA}$ & $4.31 b B$ & $* *$ \\
\hline & ANOVA & öd & öd & & * & $* *$ & \\
\hline \multirow{3}{*}{$\begin{array}{l}\text { Derinlik } \\
(\mathrm{cm})\end{array}$} & \multirow{3}{*}{$\begin{array}{l}\text { Toprak İşleme } \\
\text { Metodu }\end{array}$} & \multicolumn{3}{|c|}{$\mathrm{Zn}\left(\mathrm{mg} \mathrm{kg}^{-1}\right)$} & \multicolumn{3}{|c|}{$\mathrm{Cu}\left(\mathrm{mg} \mathrm{kg}^{-1}\right)$} \\
\hline & & \multicolumn{2}{|c|}{ Dönem } & ANOVA & \multicolumn{2}{|c|}{ Dönem } & ANOVA \\
\hline & & 1. Y11 & 2. Y11 & (Dönem) & 1. Y11 & 2. Y11 & (Dönem) \\
\hline \multirow{4}{*}{$0-10$} & Kontrol & $0.467 \mathrm{aB}$ & $1.180 \mathrm{aA}$ & $*$ & $3.61 \mathrm{bA}$ & $2.08 \mathrm{cB}$ & $*$ \\
\hline & Diskaro & $0.256 \mathrm{bB}$ & $0.358 \mathrm{bA}$ & $*$ & $3.22 \mathrm{bB}$ & $5.49 \mathrm{bA}$ & $* *$ \\
\hline & Freze & $0.380 \mathrm{a}$ & $0.430 \mathrm{~b}$ & öd & $6.13 \mathrm{a}$ & $7.73 \mathrm{a}$ & öd \\
\hline & ANOVA $^{3}$ & $*$ & $* * *$ & & $* *$ & $* * *$ & \\
\hline \multirow{4}{*}{$10-20$} & Kontrol & $0.346 \mathrm{~B}$ & $0.916 \mathrm{aA}$ & $*$ & 3.41 & $2.57 \mathrm{c}$ & öd \\
\hline & Diskaro & 0.263 & $0.208 b$ & öd & 3.02 & $3.92 b$ & öd \\
\hline & Freze & $0.344 \mathrm{~A}$ & $0.191 \mathrm{bB}$ & $* *$ & 2.77B & $6.84 \mathrm{aA}$ & $* *$ \\
\hline & ANOVA & öd & $* * *$ & & öd & $* * *$ & \\
\hline
\end{tabular}

1. Değerler 5 tekerrür ortalamasıdır. 2. Aynı harfle gösterilmeyen değerler arasındaki farklar $\% 5$ düzeyinde önemlidir. 3. öd: Önemli değil, *: \%5 düzeyinde önemli, **: \%1 düzeyinde önemli, ***: \%0.1 düzeyinde önemli.

gerçekleştirilen PBA uygulamaları toprağın $\mathrm{Cu}^{+2}$ kapsamında artış sağlamıştır. Bununla birlikte, $0-10 \mathrm{~cm}$ toprak derinliğinde diskaro, $10-20 \mathrm{~cm}$ toprak derinliğinde ise freze ile yapılan PBA uygulamaları dönemler arasında istatistikî anlamda önemli farklılıklar meydana getirmiş ve her iki uygulama ile toprağın $\mathrm{Cu}^{+2}$ kapsamında artış elde edilmiştir (Çizelge 6).

Akdeniz ekosistemindeki degrede olmuş toprakların yapısal özelliklerinin iyileştirilmesi ve korunumu amacıyla organik madde uygulanmasının gerektiği birçok çalışmada (Bastida ve ark. 2007; Fernandez ve ark. 2009) önemle vurgulanmıştır. Organik atıklar toprak özelliklerinin geliştirilmesinde ve degrede olan toprakların biyo-remidasyonunda başarılı bir şekilde kullanılmaktadır (Ros ve ark. 2003; Bastida ve ark. 2008; Tejada ve ark. 2009). Budama atıklarının toprak özellikleri üzerine etkinliğine ait yapılan birçok çalışma yapılmış ve bu çalışmalarda budama atığı uygulamalarının toprakların organik madde kapsamlarını arttırdığ ark. 2003; Karlen ve ark. 2003), hacim ağırlığını azalttığ1 (Weber 1978; Nemati ve ark. 2000) ayrica toprak karbon miktarını arttırarak toprağın yarayışlı nem kapasitesinde artış sağladığ 1 ifade edilmektedir (Emerson ve McGray 2003; Wolf ve Snyder 2003).

PBA uygulamaları ile toprağın makro ve mikro bitki besin madde kapsamında farklı sonuçlar elde edilmiştir. Özellikle denemenin ikinci yılında makro bitki besin elementlerinden azot, fosfor, potasyum ve kalsiyumun mikro elementlerden ise çinko miktarının toprakta artması PBA'nın toprağın bitki besin elementi açısından önemli bir kaynak olabileceğini ortaya koymuştur. Nitekim yapılan çalışmaların ekseriyetinde organik uygulamalar ile azot başta olmak üzere toprakların makro element kapsamlarında önemli artışlar elde edildiği ancak özellikle azot açısından bu kazanımlardaki artışın toprağın işlenmediği ortamlarda daha yüksek olduğu bildirilmektedir
(Duxbury ve ark. 1989; Baldock ve Nelson 1999; Gleixner ve ark. 2002).

Denemenin ilk yılında PBA uygulamaları ile toprağın N kapsamında azalma meydana gelirken ikinci yılda ciddi artışlar kaydedilmiştir. Toprağın $\mathrm{N}$ içeriğinde elde edilen ciddi artı̧̧larda atık uygulamalarının yanında standart olarak yapılan azotlu gübrelemelerinde etkili olduğu düşünülmektedir. Özellikle ilk yıl toprağın atık uygulamalarıyla N kapsamının düşmesi birçok literatür (Kiem ve Kogel-Knabner 2003; Marschner ve ark. 2008) bilgileriyle de uyum içindedir. Nitekim bu konuda yapılmış çalışmalarda yüksek lignin içeriğine bağlı olarak materyallerin ayrıştırılmasında rol alan mikroorganizmaların mevcut azot kaynaklarını hızla tüketmelerinin etkili bir faktör olduğu ifade edilmektedir. Bununla birlikte, toprağın demir (Fe), mangan (Mn) ve çinko (Zn) kapsamlarında istatistiksel önemliliğin bulunduğu PBA uygulamaları ile ve özellikle de denemenin ikinci yılında azalma meydana gelmiştir. Elde edilen bu sonuçta materyallerin ayrışma ürünlerinin bu mikro elementler ile yaptı̆̆ yapıların rolü olabileceği düşünülmektedir.

\section{Sonuç ve Öneri}

İki farklı toprak işleme aletiyle yapılan portakal budama atığ1 (PBA) uygulamalarının özellikle toprağın hacim ağırlığında azalma, yarayışlı su, organik madde, katyon değişim kapasitesi ile azot ve fosfor başta olmak üzere birçok makro bitki besin elementlerinde önemli artış sağlamasının toprak verimliliğinin geliştirilmesine katkı sağlamada tercih edilebilecek materyaller olabileceğini ortaya koymaktadır. Araştırmada özellikle denemenin ikinci yılında PBA uygulamalarıyla toprağın EC değerlerinde elde edilen artışların tarımsal açıdan önemli bir risk oluşturmadığı, PBA'nın uygulama süresine bağlı olarak genel anlamda toprak $\mathrm{pH}$ 
değerlerinde azda olsa bir düşüş sağlamasının yüksek kireç ve yüksek pH değerine sahip bölge toprakları açısından önemli olabileceğini göstermektedir.

Farklı toprak işleme yöntemleri dikkate alındığında; toprağın fiziksel özellikleriyle beraber makro ve mikro element kapsamının genellikle diskaro ile yapılan PBA uygulamalarında önemli değişime uğradığı belirlenmiştir.

Özetle belirtmek gerekirse uygulanan portakal budama atıklarının toprak verimlilik parametreleri üzerine olan etkinlik düzeyinin;

a) PBA'nın yapısal bileşimine,

b) PBA'nın uygulama süresine,

c) PBA'nın toprağa uygulanış yöntemine bağlı olarak geliştiği bu nedenle yüksek yoğunlukta ve daha küçük boyuttaki PBA'nın azaltılmış toprak işlemeyle birlikte uygulanmasının toprak verimlilik parametreleri üzerinde daha etkili olacağ bununla birlikte bu gibi atıkların daha uzun dönemde denenerek etkinlik düzeylerinin izlenmesinin yarar sağlayacağ öngörülmektedir.

\section{Teşekkür}

$\mathrm{Bu}$ çalışma Akdeniz Üniversitesi Bilimsel Araştırma Projeleri Yönetim Birimi tarafindan desteklenen 2011.01.0104.001 nolu projenin bir kısmını içermektedir. Desteklerinden dolayı Akdeniz Üniversitesi Bilimsel Araştırma Projeleri Yönetim Birimi ne teşekkür ederiz.

\section{Kaynaklar}

Baldock JA, Nelson PN (1999) Soil Organic Matter. In 'Handbook of Soil Science. Ed M. E. Sumner., CRC Press: Boca Raton, USA, pp. B25-B84.

Bastida F, Moreno JL, García C, Hernàndez T (2007) Addition of urban waste to semiarid degraded soil: Long-term effect. Pedosphere 17: 557-567.

Bastida F, Kandeler E, Moreno JL, Ros M, Hernandez T, García C (2008) Application of fresh and compost organic wastes modifies structure, size and activity of soil microbial community under semiarid climate. Applied Soil Ecology 40: 318-329.

Başçetinçelik A, Öztürk H, Karaca C, Kaçıra M, Ekinci K, Baban A, Kaya D, Barnes I, Komiotti N, Nieminen M (2005) Türkiye'de tarımsal atıkların değerlendirilmesi. Eğitim Programı Notları. Bursa, Türkiye, s. 15-25.

Black CA (1965) Methods of Soil Analaysis. Part:2. Amer. Soc. Of Agronomy Inc., Publisher Madisson, Wisconsin, USA. 1372-1376.

Bouyoucos GJ (1953). An improved type of soil hydrometer. Soil Science 76: 377-378.

César N, Hernández T, García C (2009) Organic Waste Amendment as Strategy for Fixing Carbon and Combating Soil Degradation in Semiarid Areas. Conferences \& Workshops Conference: ISWA World Congress 2009, Lisbon.

Chapman ND, Pratt PF (1961) methods of analysis for soils, plants and waters. Univiversity of California Division of Agriculture Science 1-309.

Chaudhuri S, McDonald LM, Skousen J, Pena-Yewtukhiw EM (2013) Soil organic carbon molecular properties: Effects of time since reclamation in a minesoil chronosequence. Land Degradation \& Development 26(3): 237-348.

Çağlar KÖ (1949) Toprak Bilgisi. Ankara Üniversitesi Ziraat Fak., Yayınlar1. Say1: 10.

Çanakçı M, Topakçı M, Ağsaran B, Karayel D (2010) Kuyruk Milinden Hareketli Budama Artığı Parçalama Makinasının Temel
İşletmecilik Verilerinin Belirlenmesi. Tarım Bilimleri Dergisi 16: 46-54.

Dalal R, Strong WM, Weston EJ, Cooper JE, Lehane KJ, King AJ, Chicken CJ (1995) Sustaining Productivity of a Vertisol at Warra, Queensland, with Fertilizers, no-tillage or legumes. 1. Organic Matter Status. Australian Jornal of Experimental Agriculture 35, 903-13.

Demiralay İ (1993) Toprak fiziksel analizleri. Atatürk Üniversitesi Ziraat Fakültesi Yayınları No: 143, Erzurum, s. 131.

DIN (1978) Torf für gartenbau and landwirtshaft (DIN: 11542).

Directive EU (2008) DIRECTIVE 2008/98/EC of the European Parliament and of the Council of 19 November 2008. http://ec.europa.eu/environment/waste/framework/.

Duxbury JM, Smith MS, Doran JW (1989). Soil organic matter as a source and a sink of plant nutrients. In 'Dynamics of soil organic matter in tropical ecosystems. Eds D. C. Coleman, J. M. Oades, and G. Uehara, (University of Hawaii Press: Honolulu), pp. 33-67.

European Environment Agency (EEA) (2000) Down to Earth, Soil Degradation and Sustainable Development in Europe. Environmental Issues Series No 16; Office for Official Publications of the European Communities: Luxembourg. pp. 32.

Emerson WW, McGarry D (2003) Organic carbon and soil porosity. Australian Journal of Soil Research 41: 107-118.

Fernàndez JM, Senesi N, Plaza C, Brunetti G, Polo A (2009) Effects of composted and thermally dried sewage sludges on soil and soil humic acid properties. Pedosphere 19: 281-291.

Gleixner G, Poirier N, Bol R, Balesdent J (2002) Molecular dynamics of organic matter in a cultivated soil. Organic Geochemistry 33: 357366.

Hueso-González P, Martínez-Murillo JF, Ruız-Sınoga JD (2014) The Impact of organic amendments on forest soil properties under mediterranean climatic conditions. Land Degradation \& Development 25: 604-612.

Jackson MC (1967). Soil Chemical Analysis. Prentice Hall of India Private Limited, New Delhi, India.

Jiménez MN, Fernández-Ondoño E, Ripoll MA, Castro-Rodríguez J, Huntsinger L, Bruno NF (2013) Stones and organic mulches improve the Quercus ilex L. afforestation success under Mediterranean climatic conditions. Land Degradation \& Development. doi: 10.1002/ ldr.2250.

Juo ASR, Lal R (1997) The effects of fallow and continuous cultivation on the chemical and physical properties of an Ultisol. Plant and Soil 35: 567-568.

Kacar B (1995) Toprak analizleri. Bitki ve toprağın kimyasal analizleri: III. Ankara Üniversitesi Ziraat Fakültesi Eğitim Araştırma ve Geliştirme Vakfı Yayınları. No: 3, Ankara, s. 705.

Kacar B, Inal A (2008) Bitki Analizleri. Nobel Yayıncılık, No: 1241. I. Bask1, ISBN 978-605-395-036-3.

Karlen DL, Ditzler CA, Andrews SS (2003) Soil quality: why and how? Geoderma 114, 145-156.

Kiem R, Kogel-Knabner I (2003) Contribution of lignin and polysaccharides to the refractory carbon pool in C-depleted arable soils. Soil Biology and Biochemistry 35: 101-118.

Lee KE, Pankhurst CE (1992) Soil Organisms and Sustainable Productivity. Australian Journal of Soil Research 30: 855-92.

Lindsay WL, Norwell WA (1978) Development of a DTPA soil test for zinc, iron, manganese and copper. Soil Science Society of America Journal 42(3): 421-428.

Lopez-Bermudez F (1990) Soil erosion by water on the desertification of a semi-arid Mediterranean fluvial basin: The Segura basin, Spain. Agriculture, Ecosystems \& Environment 33: 129-145.

Marschner B, Brodowski S, Dreves A, Gleixner G, Gude A, Grootes PM, Hamer U, Heim A, Jandl G, Ji R, Kaiser K, Kalbitz K, Kramer 
C, Leinweber P, Rethemeyer J, Schaffer A, Schmidt MWI, Schwark L, Wiesenberg GLB (2008) How relevant is recalcitrance for the stabilization of organic matter in soils? Journal of Plant Nutrition and Soil Science 171: 91-110.

Meteoroloji Genel Müdürlüğü (2015) http://www.mgm.gov.tr/veridegerlendirme/yillik-toplam-yagisverileri.aspx? $\mathrm{m}=$ antalya\#sfB

Nemati MR, Caron J, Gallichand J (2000) Using paper de-inking sludge to maintain soil structural form: Field measurements. Soil Science Society of America Journal 64: 275-285.

Norfleet ML, Ditzler CA, Puckett WE, Grossman RB, Shaw JN (2003) Soil quality and its relationshıp to pedology. Soil Science 168(3): 149-155.

Novara A, Gristina L, Bodì MB, Cerdà A (2011) The impact of fire on redistribution of soil organic matter on a mediterranean hillslope under maquia vegetation type. Land Degradation \& Development 22: $530-536$

Olsen SR, Sommers EL (1982) Phosphorus Availability Indices. Phosphorus soluble in sodium bicarbonate methods of soils analysis. Part 2. Chemical and Microbiological Properties. Editors: A. L. Page. R. H. Miller. D. R. Keeney, pp. 404-430.

Rhoades JD (1982) Soluble salts, In: Page, A.L. (Ed.), Methods of Soil Analysis, Part 2, Second Edition, American Society of Agronomy,
Inc., Madison, WI, USA, p. 167-179. Agronomy Monograph No: 9.

Ros M, Hernández T, García C (2003) Bioremediation of soil degraded by sewage sludge: Effects on soil properties and erosion. Environmental Management 31: 741-747.

Shazana M, Fauziah CI, Syed Omar SR (2013) Alleviating the infertility of an acid sulphate soil by using ground basalt with or without lime and organic fertilizer under submerged conditions. Land Degradation \& Development 24: 129-140. doi: 10.1002/ldr.1111.

Şeflek AY, Çarman K, Özbek O (2006) Budama Atıklarının Parçalanmasında Kullanılan Makinanın Performans Değerlerinin İrdelenmesi. Tarım Makinaları Bilimi Dergisi 2(3): 219-224.

Tejada M, García-Martínez AM, Parrado J (2009) Effects of vermicompost composted with vinasse on soil properties, soil losses and soil restoration. Catena 77: 238-247.

Weber LR (1978) Incorporation of nonsegregated, noncomposted solid waste and soil physical properties. Journal of Environmental Quality 7: 397-400.

Wolf B, Snyder GH (2003) Sustainable Soils: The place of organic matter in sustaining soils and their productivity. Food Products Press of The Haworth Press: New York. 